\title{
A CIDADE E SEUS LOCAIS: ONDE HÁ CIÊNCIA E TECNOLOGIA?
}

\section{Marcia Borin da Cunha}

Universidade Estadual do Oeste do Paraná, Unioeste

E-mail: marcia.cunha@unioeste.br

\section{Ana Julia Cecatto}

Universidade Estadual do Oeste do Paraná, Unioeste

E-mail: anajulia.cecatto@gmail.com

\section{Douglas Henrique Santos Conerado}

Universidade Estadual do Oeste do Paraná, Unioeste

E-mail: dog.dc1@hotmail.com

\section{RESUMO:}

A Ciência e a Tecnologia (CT) fazem parte do conhecimento de uma sociedade estando presente em nossas interações culturais e em múltiplos espaços. Contudo, estas ideias são, por vezes, distorcidas ou inadequadas. Neste estudo consideramos que a CT faz parte da cidade onde residimos e temos como questão principal: Qual o entendimento de membros de uma comunidade acadêmica (universidade) sobre a CT (na cidade onde vivem)? Nossa pesquisa teve como base a técnica de entrevista denominada Snowball Sampling (bola de neve), a qual possibilitou a entrevista de 20 membros pertencentes à comunidade de uma universidade pública brasileira. Podemos apontar que a maioria dos entrevistados têm como referência de CT aliado a espaços institucionais como universidades e centros de pesquisas. Consideramos que é necessário ampliar a cultura científica dos membros desta comunidade analisada, fazendo com que estes possam perceber que há CT em vários locais.

\section{PALAVRAS-CHAVE:}

Espaço urbano, Percepções de CT, Snowball Sampling

\section{ABSTRACT:}

Science and Technology (CT) are part of the knowledge of a society, being present in our cultural interactions and in multiple spaces. These ideas are sometimes distorted or inappropriate. In this study, we consider that CT is part of the city where we live. What is the understanding of members of an academic community (university) about CT (in the city where they live)? Our research was based on the interview technique called Snowball Sampling (snowball), which allowed the interview of 20 members belonging to the community of a Brazilian public university. We can point out that 
most interviewees have CT as a reference allied to institutional spaces such as universities and research centers. We believe that it is necessary to expand the scientific culture of the members of this analyzed community, making them realize that there is TC in several places.

\section{KEYWORDS:}

Urban space, Science and Technology Perceptions, Snowball Sampling 


\section{INTRODUÇÃO}

A percepção da Ciência e Tecnologia (CT) e como os indivíduos a percebem na sociedade é um tema que merece ser avaliado em pesquisas no Ensino de Ciências, pois tais percepções influenciam, direta e indiretamente, na compreensão da Ciência escolar. Além disso, conhecer as atitudes e as opiniões das pessoas sobre Ciência e Tecnologia e suas implicações econômicas, políticas ou éticas é importante para a formulação e a avaliação das políticas públicas (CGEE, 2017). Esse conhecimento favorece a inclusão social, a compreensão dos processos ligados à aceitação ou à rejeição das inovações científicas e tecnológicas, ainda, promove o aperfeiçoamento de modelos de popularização da ciência e do ensino de ciências.

Neste contexto, compreender a cultura científica é importante não apenas na pesquisa acadêmica, mas também na construção de políticas públicas direcionadas às áreas de educação/ensino e nas pesquisas em Ciência e Tecnologia, bem como para a avaliação da competitividade científica e tecnológica das nações.

A Ciência e a Tecnologia fazem parte do conhecimento humano, sendo resultante de nossas interações culturais e se encontra presente tanto em espaços não-formais quanto em espaços formais de educação. O tema Ciência e Tecnologia faz parte da cultura geral de uma sociedade, não sendo privilégio dos cientistas. Seu entendimento, por parte da população, chega via meios de divulgação científica, que é feita pela mídia. Contudo, por diversos fatores (inclusive pela divulgação científica que chega até a população) nem sempre há a compreensão adequada sobre o que representa a Ciência e a Tecnologia em nossas vidas e, até mesmo, o quanto estamos diariamente interagindo com seus processos e produtos. Um exemplo de compreensão inadequada do assunto é associar que a CT está voltada a apenas 
"certos membros da sociedade" e, ainda, assumir que só esses têm acesso e capacidade de produzir, utilizar e manuseá-las.

Buscando abordar este tema, Pérez et al. (2001) trazem, em seu trabalho, as visões deformadas do trabalho científico e modos de romper os pré-conceitos criados ao longo do tempo. Observa que a cultura científica é muito mais que uma "quantidade" de conhecimentos acumulados por indivíduos, pois é algo constituído ao longo da vida e está diretamente relacionada à interação do indivíduo no seu contexto sociocultural. Nesse contexto, estão presentes as diferentes experiências em relação à Ciência e Tecnologia, experiências que vão desde práticas institucionalizadas (como escola, centros de ciências, museus etc.) até as nossas relações cotidianas com a família e com os amigos (CUNHA; CECATTO; CONERADO, 2019).

A Ciência e a Tecnologia estão presentes de diferentes modos na nossa sociedade, explicitamente e/ou implicitamente. Pesquisar sobre as percepções acerca disso auxilia na compreensão do cenário vivido e atual, assim como em formas e possibilidades para uma divulgação científica adequada, que leve até o público leigo pontos de discussão sobre o papel da CT em nossas vidas, assim como os seus limites.

Pesquisas amplas sobre percepções da CT têm sido realizadas em diferentes países desde a década de 1950. A primeira enquete sobre a percepção pública da Ciência foi organizada nos Estados Unidos (EUA), em 1957, pela National Association of Science Writers (NASW) [Associação Nacional de Escritores de Ciência]. A partir desta pesquisa, o governo norte-americano passou a investir em vários setores ligados à CT, possibilitando a escalada deste país frente à outras potencias mundiais, como, por exemplo, a União Soviética (atual Rússia). 
No Brasil, a primeira enquete sobre o que o brasileiro pensa sobre a Ciência e a Tecnologia aconteceu no ano de 1987 e a última enquete realizada pelo Centro de Gestão e Estudos Estratégicos (CGEE) aconteceu no ano de 2019, apontando que, embora o interesse da população sobre o tema tenha aumentado durante os anos, não se tem obtido o entendimento real sobre CT por parte das pessoas.

Além destes dados, no presente momento, o Brasil passa por uma crise educacional e científica, onde uma parcela da população não tem depositado confiança na Ciência, ocorrendo uma desvalorização dos institutos que se dedicam à pesquisa; do mesmo modo que a educação vem sendo desvalorizada, inclusive com cortes orçamentários profundos por parte do governo. Neste cenário confuso e controverso é que buscamos investigar como membros de uma comunidade acadêmica percebem a Ciência e Tecnologia na cidade onde residem. Buscamos compreender se um grupo de indivíduos (amostra da pesquisa) percebem que a CT está presente em diferentes espaços, e vislumbramos que os conhecimentos em CT são importantes para entendimento do espaço que habitamos e, no qual, interagimos. Este é o nosso espaço de interlocução que é um recorte de uma pesquisa mais ampla que considera a cidade como um museu aberto de Ciência e Tecnologia e, no qual, há possibilidades para discutir temas relacionados ao ensino de Ciências escolar. Assim, temos como problema de pesquisa: Como os membros de uma comunidade acadêmica (universidade) percebem a CT na cidade onde vivem? 
Para responder esta questão analisaremos como esses membros percebem a CT no espaço urbano (a cidade), identificando quais são as percepções de CT dos entrevistados. Nossas análises estão relacionadas às relações feitas dos sujeitos entrevistados com o espaço urbano e buscam compreender como as pessoas reconhecem o espaço urbano como local de interação direta e indireta com a Ciência e a Tecnologia.

\section{FUNDAMENTAÇÃO TEÓRICA}

Alguns estudos realizados com o tema em didática das ciências demostram que até mesmo os professores possuem uma visão inadequada da natureza da Ciência. Assim, a imagem de Ciência e dos processos da comunidade científica é apresentada como desligada dos problemas reais do mundo, demasiado tecnicista, especializada e elitista, só acessível à privilegiados detentores do saber, existindo um desconhecimento das interações, Ciência-Tecnologia-Sociedade (PÉREZ et al., 2001).

Outro ponto que os autores destacam é que há uma

[...] divisão parcelar dos estudos, o seu carácter limitado, simplificador. Porém, esquece os esforços posteriores de unificação e de construção de corpos coerentes de conhecimentos cada vez mais amplos, ou o tratamento de "problemas-ponte" entre diferentes campos de conhecimento que podem chegar a unificar-se, como já se verificou tantas vezes e que a História da Ciência evidencia [...] (PÉREZ et al., 2001. p. 132).

Podemos observar que na área de educação os diversos ramos da Ciência são estudados de modo fragmentado, muitas vezes, sem relação entre eles, consequentemente, tem-se a formação de cidadãos com visões igualmente fragmentadas de Ciência. 
A fragmentação do conhecimento leva à compreensão de que a Ciência é um corpo isolado de conhecimento, sem que se leve em conta as suas implicações sociais. Esse pensamento é o que podemos chamar de "visão tradicional", ou visão "positivista da ciência", que define Ciência como atividade científica, cujo único fim é o desenvolvimento de conhecimentos que "descobrem" novas verdades (GORDILLO et al., 2001).

Referindo-se à Tecnologia percebe-se que a sociedade está cada vez mais dependente das inovações tecnológicas que, por sua vez, criam demandas, levando ao aumento do gasto de energia e consumo de matérias-primas. Homens e mulheres passam a adquirir novos modos de vida, estando vulneráveis ao consumo exagerado de produtos oriundos da Tecnologia, causando o exagerado consumismo, endividamento da população, degradação ambiental, entre outros.

Outro ponto de destaque, nas percepções de CT, é afirmar que a Ciência e Tecnologia são práticas neutras, e que somente quando o ser humano faz uso inadequado destas é que temos consequências sociais. Pensar desta forma é o mesmo que dizer que a Ciência e a Tecnologia estão isentas de qualquer tipo de interesse particular, tanto em sua concepção e desenvolvimento, como nos resultados. (CANDEÓ; SILVEIRA; MATOS, 2014).

Apesar de muito ter-se defendido, a ideia da Tecnologia como Ciência aplicada, hoje é difícil aceitá-la, como afirma Bazzo, Pereira e Von Linsingen (2000). Esta imagem reduz o papel da Tecnologia na sociedade, pois admite que apenas existe Tecnologia, se existir anteriormente a Ciência. 
A imagem da tecnologia como ciência aplicada contribui para que tradicionalmente se dê pouca importância à análise da tecnologia. De fato, quando se sustenta que a tecnologia não é mais do que a ciência aplicada, é suficiente a análise da ciência, já que isso nos dará a chave para entender também a tecnologia [...] (BAZZO; PEREIRA; VON LINSINGEN, 2000, p. 42).

De modo geral, podemos dizer que Tecnologia é definida como sendo uma técnica ou conjunto de técnicas de domínio particular ou de algum grupo específico, não necessariamente exigindo um estudo ou uma Ciência que a antecede. Entender e identificar essas deficiências no meio social auxilia para a formação de cidadãos menos alienados e sem opinião sobre os acontecimentos que os cercam.

A CT é vista, por muitos indivíduos, como produtoras de conhecimento significativo e detentora de poder nas sociedades contemporâneas. Neste cenário complexo, devem circunscrever-se os temas relacionados à cultura científica de uma sociedade, suas limitações e possibilidades, não somente como forma de aumentar a educação científica das pessoas, mas também como forma de traçar os destinos da própria Ciência.

A cultura científica faz parte do contexto da sociedade, porém é de difícil definição, assim como delimitar que um indivíduo tem uma "boa" cultura científica. A formação de uma cultura científica está atrelada à processos de comunicação pública da Ciência (com destaque aos Museus e Centros de Ciência), a divulgação da Ciência nas diferentes mídias e aos conceitos formais de Ciência na escola, dentre outras experiências informais, como família, amigos, entre outros. No que se refere aos Museus e Centros de Ciência podemos dizer que essas instituições são capazes de conectar o público em geral com os avanços e assuntos relacionados à CT. O objetivo maior destes espaços é possibilitar e ampliar a consciência dos indivíduos sobre o 
papel e a importância da CT na sociedade. São espaços que proporcionam experiências educativas a quem os visita. De modo geral (no Brasil), estes espaços estão localizados nas capitais e grandes centros, o que impossibilita ou dificulta que pessoas residentes em locais distantes destes centros possam desfrutar de experiências deste gênero. Considerando a falta de Museus e Centros de Ciência em cidades fora das capitais (como é o caso da cidade onde se realizou esta pesquisa) é que apostamos que a cidade é um espaço repleto de Ciência e Tecnologia e que deve assim ser percebida, bem como utilizada pela escola como meio para discutir CT, ampliando a cultura científica dos estudantes.

Definir "cidade" é sempre uma tarefa difícil, pois, ao pensar em "cidade" nunca estamos diante de uma, mas dentro dela. Por isso, a cidade é um aglomerado de fatos e histórias que moldam a relação homem/natureza. Segundo Lefebvre (2001), a cidade é considerada como obra de certos "agentes" históricos e sociais. Isto leva a distinguir a ação e o resultado, o grupo e seu produto. Lefebvre afirma ainda que,

[...] a cidade sempre teve relações com a sociedade no seu conjunto, com a sua composição e seu funcionamento, com seus elementos constituintes (campo e agricultura, poder defensivo e ofensivo, poderes políticos, estados, etc.), com sua história. Portanto, ela muda quando muda a sociedade no seu conjunto. Entretanto, as transformações da cidade não são resultados passivos da globalidade social, de suas modificações. A cidade depende também e não menos essencialmente das relações de imediatice, das relações diretas entre as pessoas e grupos que compõem a sociedade [...] (LEFEBVRE, 2001, p. 46). 
Entende-se que a cidade não é um espaço físico atemporal e imutável, mas um espaço que depende da sociedade que o constitui, refletindo suas características e costumes.

A cidade se transforma não apenas em razão de "processos globais" relativamente contínuos (tais como o crescimento da produção material no decorrer das épocas, com suas consequências nas trocas, ou no desenvolvimento da racionalidade) como também em função de modificações profundas no modo de produção, nas relações "cidade-campo", nas relações de classe e de propriedade. [...] (LEFEBVRE, 2001, p. 53).

O autor reforça a premissa sobre a cidade como construção humana, pois segundo ele, a cidade é ao mesmo tempo local e meio das interações humanas. (LEFEBVRE, 2001). Dessa forma, dizemos que a cidade é resultado da cultura local e das ações humanas, sendo constituída por um aglomerado de pessoas, objetos, leis etc., ou seja, um excelente local a ser explorado em atividades didáticas.

Considerando a existência de amplos elementos na cidade podemos perguntar: Será que os indivíduos conseguem observar a cidade além de um local de moradia e trabalho? Será que esses indivíduos percebem o quanto a cidade pode ser explorada para se estudar temas relacionados a CT? Por meio dessas indagações surgiu a necessidade de investigar quais as percepções dos membros da sociedade sobre o espaço em que vivem e a ideia de CT na cidade. Esse caminho pode nos levar a ações extensionistas da universidade, como forma de melhorar as percepções sobre o tema $\mathrm{CT}$, bem como a ideia da cidade como Museu Aberto. Além disso, entender as percepções dos membros da sociedade sobre o espaço em que vivem nos remete a refletir sobre o papel da escola na formação dos cidadãos e nos processos de ensinar Ciências. 


\section{Metodologia}

Esta pesquisa é de cunho qualitativo do tipo estudo de caso e utilizou como técnica para construção dos dados o modelo de pesquisa Snowball Sampling (bola de neve). Essa técnica constitui-se como uma amostra não probabilística, utilizada geralmente em pesquisas no meio social, na qual os participantes iniciais do estudo indicam novos participantes que, por sua vez, indicam outros participantes e assim sucessivamente, até que seja alcançado o objetivo proposto o "ponto de saturação". O "ponto de saturação" é atingido quando novos entrevistados passam a repetir os conteúdos já obtidos em entrevistas anteriores, sem acrescentar novas informações. Para Baldin e Munhoz (2011) esta é uma técnica de amostragem que se utiliza de uma cadeia de referências, como uma rede.

No caso específico deste estudo, o campo de pesquisa foi um campus da Universidade Estadual do Oeste do Paraná, Unioeste, sendo que o primeiro entrevistado foi um docente que pertence a um centro/departamento diretamente relacionado à Ciência e Tecnologia, denominado "Centro de Engenharias e Ciências Exatas".

A partir do primeiro entrevistado, este, por meio de escolha livre, fez a indicação do próximo a ser entrevistado, considerando esta indicação pertencente à comunidade universitária a qual ele pertencia e onde estava sendo realizada a pesquisa. Consideramos como comunidade universitária os docentes, discentes, funcionários, administradores etc.

A pesquisa foi conduzida com entrevistas individuais semiestruturadas, que foram orientadas por um roteiro/guia e teve como objetivo conduzir a conversa/entrevista de forma aberta, mas com objetivo definido. Para registro das 
entrevistas e posterior análise foi utilizada a gravação em áudio, com posterior transcrição das falas, que foram realizadas por meio da audição e digitação, a fim de obterem-se dados qualitativos. As gravações foram transcritas e analisadas considerando-se o problema proposto, ou seja, como os entrevistados percebem a Ciência e a Tecnologia na cidade onde residem (o espaço urbano). Todos os entrevistados assinaram o termo de consentimento.

Neste artigo trazemos os resultados obtidos ao questionar o entrevistado sobre os locais onde há Ciência e Tecnologia na cidade, e para a análise das entrevistas foram determinadas categorias e subcategorias, sendo que estas emergiram a partir da fala dos entrevistados.

Os entrevistados foram identificados de forma sequencial, sendo E1 para o primeiro e E20 para o último. No texto, utilizamos a forma "o" para representar "o entrevistado", assim não será considerado o gênero feminino e masculino, apesar da amostra contemplar ambos.

\section{RESULTADOS}

Apresentaremos os resultados por categoria e subcategoria. Trazemos para discussão recortes das falas que tiveram origem nas entrevistas realizadas e transcritas. Diante das entrevistas foi possível definir algumas categorias em relação aos locais indicados pelos entrevistados, onde é possível perceber a presença da Ciência e da Tecnologia na cidade. No quadro 1 apresentamos as categorias, subcategorias e a indicação de cada entrevistado, nas quais foi possível perceber elementos que justifiquem a categoria e a subcategoria. 
Quadro 1: Categorias, subcategorias e entrevistados. Fonte: Os Autores.

\begin{tabular}{|c|c|c|}
\hline Categorias & Subcategorias & Entrevistados \\
\hline \multirow{3}{*}{ Institucional } & Universidades & E2, E3, E12, E17, E19 \\
\hline & Centro de pesquisa & E5 \\
\hline & Museu & E11 \\
\hline Não Institucional & Parque & E1, E6, E10, E16 \\
\hline \multirow{3}{*}{ Comercial } & Fábricas & E9, E13 \\
\hline & Fábrica/Indústria e laboratório & E8 \\
\hline & $\begin{array}{c}\text { Padaria e laboratório de análises } \\
\text { clínicas }\end{array}$ & E15 \\
\hline \multirow{2}{*}{$\begin{array}{l}\text { Institucional e } \\
\text { Comercial }\end{array}$} & $\begin{array}{l}\text { Universidade/Fábrica/ } \\
\text { Indústria e laboratório }\end{array}$ & E4 \\
\hline & Universidades e Fábricas & E20 \\
\hline Múltiplos ambientes & ----- & E18 \\
\hline $\begin{array}{l}\text { Universidade, } \\
\text { indústria, carros }\end{array}$ & ----- & E7 \\
\hline Não percebido & ----- & E13 \\
\hline
\end{tabular}

\section{Categoria 1: Institucional}

Nesta categoria trazemos as referências apresentadas pelos entrevistados quando estes mencionam espaços institucionais, como é o caso das universidades, centros de pesquisa e museu.

\section{Subcategoria: universidades}

E2 nos diz que entende que como as universidades fazem pesquisa essas têm Ciência e que nestes espaços é possível ter alguma informação sobre CT:

"[...] sei que envolve pesquisa científica dentro desse campus, e aqui na [...] e na [...], na [...] eu não sei como que tá, mas... sendo uma faculdade... alguma pesquisa deve existir, não sei no campo da ciência e tecnologia exatamente". 
E3 apresenta uma resposta bastante sintética para a questão, a qual considera que a universidade onde ele estuda é um no qual a CT pode ser percebida. Sua resposta se resume a seguinte frase: "ah própria [...] pode ser um centro."

Durante a entrevista com E12 este respondeu que considera que as universidades são locais que por excelência "fazem" ciência, tendo projetos mais ou menos "ousados". Salienta que a [...] em especial tem "muitas frentes de pesquisas", mas que: "[...] não necessariamente produzem um resultado tecnológico imediato também, mas as pesquisas que fazemos aqui ou a pesquisa que se faz em qualquer lugar do mundo, é por excelência uma ampliação do horizonte do conhecimento". Acrescenta ainda que, em alguns casos, a publicação de um determinado trabalho é demorada, mas que a Ciência está sempre vinculada à inovação e, desta forma, direcionada à Tecnologia.

E17 respondeu que, em geral, as pessoas associam a produção tecnológica às universidades e associam Ciência com Tecnologia, ou, o que ele denomina, como tecnociência. Complementa a sua ideia dizendo que é na universidade que se aprende Ciência para compreender o mundo. Contudo E17 admite que existem outros locais onde a Ciência pode ser aprendida, não sendo necessariamente em locais de educação formal. Segundo E17: "[...] você pode fazer isso com seus pais em casa, você pode fazer isso na escola, você faz isso em vários momentos da sua vida, e continua fazendo isso, né, em qualquer ambiente que a gente chame de ambiente educacional $[\ldots]^{\prime \prime}$.

Em relação à Tecnologia E17 tem uma fala confusa, na qual podemos apenas considerar que para ele uma Tecnologia não é necessariamente ligada a "Física e a 
Química", podendo existir uma "[...] tecnologia social, em que você "bola" meios diferentes para determinadas finalidades utilizando pessoas [...]".

E17 encerra sua fala concluindo que:

"[...] ciência e tecnologia estão em todos os lugares, mas uma parte mais específica, quando a gente coloca em questão essas categorias, que a gente usa pra definir a sociedade mais ampla, a gente consegue definir isso nos ambientes universitários [...]"

E19 tem uma fala obscura e reluta inicialmente a dar resposta à nossa pergunta, então diz que, quando se fala de Ciência a universidade é o ponto "pacífico" para isto, porém não traz argumentos que justifiquem a sua ideia. Em outro momento da entrevista, ele cita que não apenas a universidade, mas também os "institutos" que estão situados na cidade e tem a "[...] implicação do uso de conhecimentos específicos para desenvolver atividades [...]" podem ser considerados locais de presença da CT. E19 justifica a sua escolha quando relaciona a aplicação da CT em "trabalhos" presentes na sociedade, e diz "[...] se você for buscar um serviço ou algum trabalho ou alguma coisa desse tipo, você vai ver que tem ciência, tem conhecimentos de ciência lá dentro, mesmo que as pessoas não percebam. E19 conclui a sua fala relacionando a Tecnologia à aplicação da Ciência, quando diz: "[...] exemplo estou no escritório e vou usar de um computador para você elaborar, o computador é uma tecnologia, que foi desenvolvida a partir de conhecimentos científicos [...]". Por esta ideia podemos dizer que E19 associa a Tecnologia aos conhecimentos científicos anteriores.

\section{Subcategoria: centro de pesquisa}

E5 começa sua fala se referindo ao lugar onde ele trabalha e faz pesquisa na área de Química. Neste contexto faz crítica à falta de Tecnologia dentro do ambiente 
universitário para auxiliar as pesquisas, o que restringe o desenvolvimento da Ciência. Acrescenta que, em alguns momentos é preciso buscar em outras universidades auxílio para desenvolver a pesquisa. Apesar de seus comentários estarem voltados à um centro de pesquisas da universidade, E5 não apresenta elementos que possam nos indicar suas ideias sobre locais onde ele percebe a CT.

Para E5, a CT está atrelada à pesquisa e, mesmo citando um centro de pesquisa em um campus universitário, ele não percebe CT voltada à comunidade, apenas para o desenvolvimento da Ciência por meio de pesquisas realizadas. Conclui que: "[...] na universidade que deveria ser um lugar onde devia ver ciência e tecnologia é visto, mas de uma maneira bastante limitada [...]"

\section{Subcategoria: museu}

E11 considera que museus são espaços que guardam um acervo para determinada consulta e que nesses espaços há a presença da Tecnologia, quando, por exemplo, não há uma pessoa que realiza o atendimento em uma máquina. Salienta que a Tecnologia está presente em vários espaços, sempre na condição de auxiliar as pessoas para a busca de informação ou atendimento. Este entrevistado traz o museu como um exemplo de CT, mas não consegue justificar esta referência, apenas lembra que a Tecnologia está presente em um museu de forma indireta. A Ciência não faz parte da fala deste entrevistado, mesmo sendo a pergunta inicial referente a ela.

\section{Categoria 2: Não institucional}

Aqui são consideradas as menções à locais da cidade como parques e, neste contexto, o lago e horto municipal.

\section{Subcategoria: parques}


E1 hesita e durante a entrevista foram necessários alguns segundos para pensar na resposta, quando nos responde que a CT está presente em alguns espaços públicos presentes na cidade como os parques, citando como exemplo: "[...] o lago municipal, o aterro, com a própria construção do lago, o parque do lago, o aquário, de certa forma isso dá um... lembra alguma coisa de ciência e tecnologia [...]". E1 ressalta que, além destes espaços públicos, existem também empresas onde ele imagina haver CT, mas que não são de livre acesso ao público, assim como acontece nos parques.

E6 tem uma fala bastante voltada ao estudo de áreas específicas, como a Física, dizendo que com um olhar voltado à percepção de CT, ao ir ao lago municipal podese estudar várias áreas do conhecimento. "[...] se você quer estudar física você estuda o movimento de alguém que está patinando, por exemplo, ou se você quer estudar química, basta você esperar o pôr do sol e analisar o porquê que tem o tom avermelhado, que são as partículas de poeira no ar [...]". E6 conclui sua fala dizendo que a CT é encontrada em todos os lugares, não sendo necessário um ponto específico como uma universidade para tal.

E10 nos fornece uma resposta rápida e bastante genérica, na qual aponta que o Lago Municipal da cidade é um ambiente propício à existência e percepção da CT, porém não é capaz de justificar a sua escolha, levando-nos a entender que a sua indicação foi baseada em uma escolha aleatória.

O entrevistado E16 cita o Lago e o Horto Municipal, mas ressalta que o lago tem toda uma estrutura que foi projetada, inclusive com o plantio de árvores que ali não existiam. Segundo o entrevistado este local pode ser um objeto de estudo. Ele percebe que todas estas alterações (no lago) se deram graças à Tecnologia. "[...] o lago municipal, uma certa estrutura ali no meio. Ter também plantado árvores nativas, o 
uso dessa de fazer uma pesquisa de quais seriam os tipos de árvores que nós temos aqui e, também, a quantidade [...]". E16 observa que a Ciência é o que pode explicar todo o projeto que deu origem ao lago, transformando um espaço "inútil" em um lugar para praticar exercícios, lazer, ponto turístico e "agrega valor econômico". Em mais de um momento da entrevista, E16 enfatiza que o lago é um bom exemplo de transformação do ambiente em benefício da cidade. O entrevistado lembra que o projeto de construção do lago é proveniente de um trabalho de conclusão de curso (TCC) de um morador da cidade.

No horto, o entrevistado cita que há árvores nativas que podem ser observadas. E16 explica que:

"[...] eu vejo que a ciência ali [...] a quantidade de água por exemplo que você precisa vazão. Se você tem a possibilidade ou não de colocar peixes, se você tem toda uma estrutura que foi agregando hoje. A gente tem o aquário municipal, quer dizer, você tem o recurso da tecnologia para o turismo, para incentivar às pessoas, para mostrar as pessoas como era [nome da cidade] antigamente, qual era o tipo de plantas que tinha etc. A ciência e a tecnologia têm um papel importante nesse setor aí, na projeção do parque $[\ldots]^{\prime \prime}$.

\section{Categoria 3: Comercial}

Consideramos como "comercial", as falas que nos remetem à fábricas e indústrias da cidade, assim como padaria e laboratórios de análises clínicas, que foram mencionados pelos entrevistados.

\section{Subcategoria: fábricas}

E9 traz uma resposta curta e genérica, pois diz que uma fábrica presente na cidade é um local onde se percebe CT e sua resposta se resume apenas ao "[nome da 
fábrica]". Esta é uma indústria de medicamentos genéricos da cidade, sendo um referencial de CT para o entrevistado E9.

O entrevistado E13 responde (sem pensar muito) e cita uma fábrica da cidade (indústria de alimentos), como um local onde "[...] percebe que tem um somatório de Ciência e Tecnologia [...]". Esse entrevistado relaciona alguns lugares desta fábrica, como, processamento de alimentos e máquinas automáticas, como derivadas do conhecimento científico.

\section{Subcategoria: fábricas/indústrias e laboratórios}

E8 relembra que seu estágio curricular do curso de graduação e diz haver CT em tudo que é "desenvolvido" e dentro das Indústrias e Laboratórios, citando como exemplo "[...] tem a [nome da indústria], tem a [nome da indústria] [...]". Este último foi um laboratório de análises físico-químicas, que funcionou por um período na cidade.

\section{Subcategoria: padaria e laboratório de análises clínicas}

O entrevistado E15, inicialmente, cita a universidade como local onde a CT está presente, mas, em seguida, relaciona a CT com um laboratório de análises clínicas e padaria, dizendo que "[...] ciência e tecnologia têm em todas as atividades em maior ou menor grau [...]". Conclui sua fala relacionando o laboratório de análises clínicas como um local onde se tem uma CT de "maior grau".

\section{Categoria 4: Institucional e comercial}

Nesta categoria agrupamos as falas que citam a universidade, as fábricas e o laboratórios de pesquisa em conjunto.

Subcategoria: universidade, fábrica e laboratório 
E4 faz uma fala breve e sintética, dizendo que na universidade se estuda CT, e que também é possível percebê-las em locais como nas fábricas e em laboratórios.

E20 cita, inicialmente, que as universidades são locais de produção de CT, ressaltando os cursos de engenharia e a importância destes para a produção de conhecimento.

"[...] engenharia de pesca é um lugar onde se produz conhecimento que está no limite em Ciência e Tecnologia, por exemplo, estudo de como fazer ração para peixe existe conhecimento teórico e esses conhecimentos práticos e têm uma aplicação imediata então o pessoal da pesca estão envolvidas na produção de peixes na região e na produção de conhecimentos [...]".

Menciona também, ao longo de sua fala, as empresas [nome da empresa] e [nome da empresa], dizendo que embora não conheça muito destes locais, imagina que neles haja uma "[...] pesquisa e há uma integração muito grande entre ciência e tecnologia [...]". Diz que a nossa vida está totalmente envolvida nas questões de CT, e cita como exemplo disso os eletrodomésticos que são adquiridos e tem todo um estudo por traz deles "[...] envolvendo as políticas dos governos estadual e federal [...]". Finaliza sua fala mencionando os estudos em torno das vacinas, que, atualmente, temos de tomar uma vacina para gripe e relaciona este ato como: "[...] que o nosso mundo [...] incorporamos a ciência e os seus resultados até de uma forma natural [...]".

\section{Categoria 5: múltiplos ambientes}

Esta categoria tem sua existência a partir de referências feitas por um entrevistado e, na qual, não há menção a um espaço específico, mas uma abordagem geral e ampla sobre diferentes espaços da cidade onde a CT se faz presente. 
O entrevistado E18 percebe a CT em vários locais da cidade como: nas centrais de TV e rádios, companhia de saneamento, indústria, telefonia, laboratórios nas escolas, leitarias, rio da cidade e construção civil. Ressalta que a Tecnologia é mais perceptível na cidade, e que em qualquer lugar dela é possível observá-la. Cita que, mesmo no interior do município, é possível observar muita Tecnologia, por exemplo, em sistemas de alimentação de animais de forma automática ou para ordenha de animais. Na construção civil, E18 observa que há forte presença da Tecnologia "[...] a construção dos prédios é com aqueles... com aqueles... não sei como se chama, aqueles braços eletrônicos que fazem... levam. Antigamente precisava de 100 homens, hoje com 10 homens e um aparelho daqueles leva todo o cimento. O cimento já vem preparado hoje, porque existe um caminhão que prepara e tudo a partir de uma ideia da alavanca e roda a tecnologia [...]". O entrevistado ainda ressalta que a tecnologia é uma forma de melhorar o "desempenho humano".

\section{Categoria 6: Indústria, universidade, carros}

Temos a categoria "indústria, universidade, carros" a partir da fala de um entrevistado que, apesar de não justificar estes locais, os menciona como locais de CT na cidade.

O entrevistado E7 menciona que as indústrias e a universidade são locais onde ele percebe $\mathrm{CT}$, porém não fornece recursos em sua fala que sustentem a sua visão e cita: [...] carros também é uma forma de tecnologia". Sua fala é breve e sem explicação.

\section{Categoria 7: não percebido}

Um dos entrevistados não percebe a CT na cidade e, deste modo, surge esta categoria. 
E13, ao ser questionado, relata que na cidade ele não percebe nenhum lugar onde possa ser observada a CT. Entretanto informa que na cidade de Foz do Iguaçu a CT existe nos "[...] artefatos montados lá da ciência, a gente chama de laboratório de ciências [...]". E13 cita que em viajem à cidade de Vitória (Espírito Santo) observou que lá existe "[...] uma praça, digamos assim... científica e todos os brinquedos que tinham lá dentro, sejam de espelhos convexos, côncavos, todos os brinquedos eram relacionados à ciência, e lá é uma praça cercada [...]". Em outra viajem à Florianópolis existia em um shopping uma exposição de artefatos de física, como por exemplo, "[...] aquele de energia estática que coloca as mãos o cabelo fica de pé, e vários outros elementos assim [...]". E13 finaliza a sua fala dizendo que "[...] por incrível que pareça não era só isso que a gente poderia associar à ciência né, mas isso que é mais evidente que tem um cuidado relacionado a ciência."

\section{DISCUSSÃO dOS RESULTADOS}

Ao indagar membros de uma comunidade universitária (estudo de caso) sobre locais na cidade em que é possível perceber aspectos de CT, observamos que, a maior parte das indicações, remetem-se à locais como a própria universidade, as fábricas, sendo estes locais de pesquisa ou com aplicação de pesquisas, isto é, locais em que fica mais evidente a presença da Ciência e da Tecnologia.

Na figura 1 apresentamos um esquema da cidade onde a pesquisa foi realizada e, nele, estão apontados os locais indicados por 19 dos 20 entrevistados, tendo em vista que um deles não fez nenhuma indicação. A figura apresentada é seguida de um quadro (Quadro 2). Neste trazemos indicações dos locais citados e a referência ao entrevistado que fez a indicação. Na última coluna é possível observar a "função" do entrevistado dentro da universidade, ou seja, é um docente, um acadêmico ou um 
funcionário. A partir deste esquema é possível perceber que as referências apresentadas, por grande parte dos entrevistados, estão localizadas em locais próximos à universidade ou a própria universidade. Este fato os leva a refletir sobre a interação destes sujeitos com o espaço urbano, desconhecendo (pelo menos de modo imediato) locais que não façam parte do seu local de trabalho e estudo, locais estes que os entrevistados devem passar maior parte do seu dia. Na figura 1 apresentamos um mapa indicando locais mencionados pelos entrevistados. O símbolo "estrela vermelha" é o local onde foi feita a pesquisa e considerado como ponto de referência para as discussões que seguem.

Figura 1: esquema das indicações dos entrevistados. Fonte: Os autores

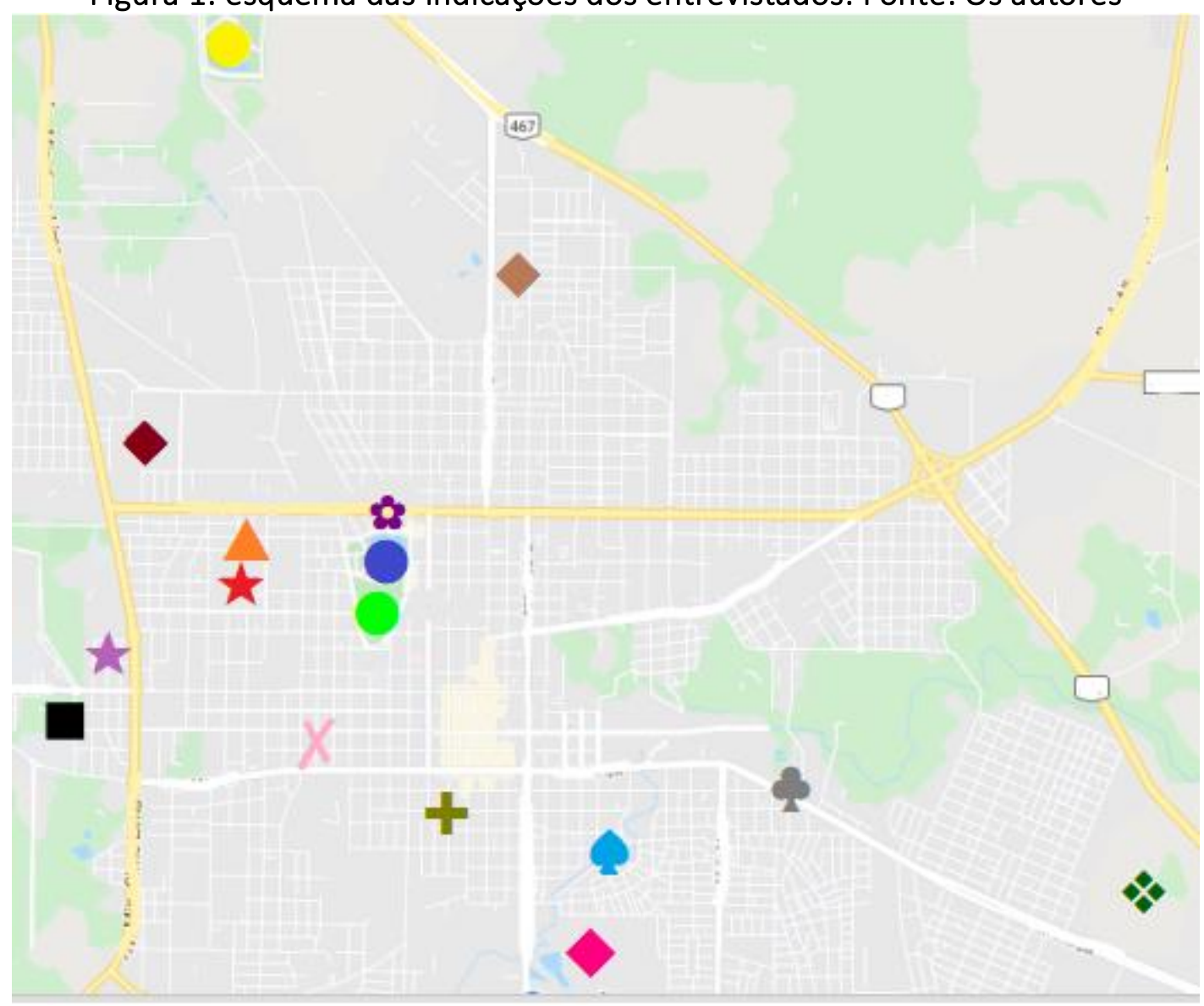


Quadro 2: relação entre os entrevistados e os locais citados. Fonte: Os autores

\begin{tabular}{|c|c|c|c|}
\hline \multicolumn{4}{|c|}{ Legenda do Mapa } \\
\hline Cores & Locais & Entrevistados & Função \\
\hline$\bullet$ & Lago Municipal & E1, E6 & Docente e estudante \\
\hline - & Horto Municipal & E16 & Docente \\
\hline (2) & Parque & E10 & Estudante \\
\hline$\star$ & Universidade 1 & $\begin{array}{c}\text { E2, E3, E12, } \\
\text { E17 }\end{array}$ & $\begin{array}{l}\text { Docente, estudante, } \\
\text { docente e docente }\end{array}$ \\
\hline$\star$ & Universidade 2 & E2 & Docente \\
\hline$\diamond$ & Indústria 1 & E4, E8, E9 & $\begin{array}{c}\text { Estudante, estudante } \\
\text { e estudante }\end{array}$ \\
\hline 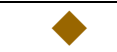 & Indústria 2 & E7 & Estudante \\
\hline$\nabla$ & Indústria 3 & E13 & Docente \\
\hline 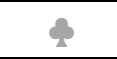 & Rua & E4 & Estudante \\
\hline - & $\begin{array}{l}\text { Museu histórico da } \\
\text { cidade }\end{array}$ & E11 & Funcionário \\
\hline $\boldsymbol{\Delta}$ & $\begin{array}{c}\text { Grupo de Pesquisas na } \\
\text { universidade } 1\end{array}$ & E5 & Estudante \\
\hline 8 & Cinema & E19 & Docente \\
\hline \& & Estrebaria & E18 & Docente \\
\hline$x$ & Panificadora & E15 & Docente \\
\hline+ & $\begin{array}{l}\text { Laboratório de } \\
\text { Análises Clínicas }\end{array}$ & E15 & Docente \\
\hline Q & $\begin{array}{c}\text { Rio que contorna a } \\
\text { cidade }\end{array}$ & E20 & Docente \\
\hline
\end{tabular}

Observamos que a maioria dos entrevistados são estudantes da universidade e, em algum momento de sua fala, fazem menção à universidade, seja nos modos de estudar e perceber o mundo, seja quando fazem referência ao local indicado ou em local onde realizaram um estágio. Quando o entrevistado é um docente, estes citam locais nos quais a CT se relaciona com a sua área de estudo. Como foram docentes de várias áreas entrevistados (Física, Química e Filosofia), as suas respostas são bem variadas, assim como as suas justificativas.

Notamos que os locais mais citados pelos entrevistados estão localizados nas imediações da universidade, onde foi realizada a pesquisa. Em uma análise geral, 
podemos dizer que os entrevistados demonstram pouco conhecimento da cidade no que se refere à $\mathrm{CT}$, ou que estes foram levados a citar algo próximo da universidade justamente por estarem nela no momento da entrevista.

Na primeira subcategoria "Universidades", percebemos que para E2 (docente) e E12 (docente) a CT estão intrinsicamente interligadas ao meio acadêmico, sendo este um local de produção da CT como conhecimento significativo e utilitário, no qual todo o conhecimento produzido nestes locais tem potencial de aplicação na sociedade, ou como fonte de informações para momentos em que estes se fazem necessários, evidenciando visões pontuais da CT. Nesta mesma categoria, E3 (estudante) tem uma visão restrita acerca do tema, pois a universidade, como um local institucional, tem os aspectos de CT bem definidos para os membros que atuam nela e para os que a observam externamente. E17 (docente) considera a universidade como local onde se aprende Ciência para compreender o mundo e, assim, diferentemente dos outros entrevistados, não relaciona a Ciência com a criação de novas tecnologias para o uso humano, mas com o descobrimento do mundo. Este entrevistado aponta que a CT não está atrelada apenas à algumas áreas do conhecimento, mas está presente em todos os locais. Embora indique a universidade, E17 tem uma visão ampla da CT, pois entende que estas não estão presentes unicamente nos meios institucionais, podendo ser percebida a CT na sociedade como um todo.

E19 (docente) tem uma visão de CT restrita, pois considera os ambientes educacionais como principais detentores de Ciência e Tecnologia e, quando amplia um pouco mais essa percepção, este relaciona a Tecnologia como produto direto da Ciência, fornecendo-nos assim uma percepção utilitarista da CT. 
Em relação a subcategoria "Museu", a percepção de E11 (funcionário) sobre locais da CT é bastante limitada e sem uma justificativa coerente. Este entrevistado cita o museu, porém sua justificativa caminha na direção de um local que contém um acervo de materiais, mas a sua justificativa está centrada na Tecnologia que permite catalogar estes materiais e que substitui o trabalho humano, quando, por exemplo, um atendimento é feito de forma automatizada.

Em relação a subcategoria "Parques", podemos dizer que E1 (docente) tem uma visão ampla da CT na cidade, pois foi capaz de citar locais diferentes, os quais não são polos de CT como as universidades apontadas por muitos entrevistados. E6 (estudante) também demonstrou percepções de CT voltadas ao estudo das diversas áreas do conhecimento. Este não aponta a universidade (inicialmente) como local de percepção de CT, porém remete suas justificativas ao estudo, levando-nos a entender que ele foi capaz de perceber CT tanto em ambientes institucionais, quanto em ambientes não institucionais.

Ao contrário dos outros entrevistados, nesta categoria E10 (estudante) aponta um parque da cidade como um local de percepção da CT, mas não é capaz de justificar, ou de fornecer elementos que reforcem sua escolha. Contudo, E16 (docente) consegue perceber CT em ambientes não institucionais e remete-se ao uso da CT como ferramenta de uso humano que altera o meio dependendo do interesse humano. Assim, E16, por mais que este perceba a CT em ambientes distintos, sua visão restringe-se a apenas agregar beleza ou economia ao município.

Na subcategoria "Fábricas", os entrevistados possuem uma visão restrita da CT, percebendo que fábricas, são locais em que a CT está sempre presente e que, nestes locais, há "aplicação" da Ciência e, em alguns momentos, pode haver também pesquisa para produção de novos produtos. 
Em relação a subcategoria "Fábricas, indústrias e laboratórios" podemos dizer que E8 (estudante) atribui à CT à produção de algum produto ou análise deste. Deste modo, E8 apresentou uma percepção reducionista da CT, pois, mesmo citando estes locais, ele não consegue avançar o seu pensamento e emitir justificativa.

Na subcategoria "Padaria e laboratório de análises clínicas", a partir da fala de E15 (docente) percebemos que a CT pode ser observada em vários locais da cidade, tanto na universidade, quanto no comércio e na prestação de serviço. Mas, seus argumentos nos levam a interpretar sua percepção de CT como algo voltado ao desenvolvimento e uso de tecnologias.

Na subcategoria "Universidade, fábrica e laboratório", por mais que E4 (estudante) aponte diversos locais onde a CT está presente, este não traz argumentos suficientes para sustentar a sua indicação, por isso dizemos que E4 possui uma visão e CT voltada ao uso de tecnologias e ao desenvolvimento de novos conhecimentos. Ainda nesta subcategoria, E20 (docente) traz em sua fala vários elementos onde a CT é perceptível, a partir destes locais indicados podemos dizer que o entrevistado possui uma visão ampla da $\mathrm{CT}$, pois percebe que a $\mathrm{CT}$ faz parte da cidade e a compreende como parte do seu dia a dia.

Na categoria "Múltiplos ambientes", o entrevistado E18 (docente) foi capaz de apresentar diversos locais onde a CT pode ser percebida, embora a perceba em diversos locais, E18 restringe a sua função apenas como meio para de melhorar o desempenho humano.

Na categoria "Carros" E7 (estudante) é bastante genérico e sem aprofundamento, apenas cita os carros como tecnologia, mas não justifica ou indica locais de Ciência na cidade. 


\section{CONSIDERAÇÕES FINAIS}

Quando comparamos as respostas dos 20 entrevistados, percebemos que a maioria (13) não possui uma percepção ampla da CT na cidade, pois estes possuem visões utilitaristas, restritas ou, ainda, reducionistas da CT. Em oposição, temos cinco (05) entrevistados que foram capazes de demonstrar percepções de CT um pouco mais aberta, indicando mais de um local que há CT. Mas, apenas um (01) entrevistado apresentou uma percepção ampla sobre a presença da Ciência e da Tecnologia em vários locais da cidade, dizendo que estes locais são difíceis de delimitar, em função da sua vasta presença no nosso meio e convívio diário. Também nos chamou a atenção o fato de um dos entrevistados não citar nenhum local onde ele percebe a CT.

Com essas análises podemos dizer que, por mais que a universidade seja um local onde a Ciência e a Tecnologia estão intrinsicamente ligadas, os membros da comunidade acadêmica ainda possuem suas percepções ligadas ao ambiente próximo em que estão inseridos (salvo alguns membros), nos indicando que há uma compreensão restrita do que significa a CT no meio em que vivem e qual a função desta na sociedade.

Se as pessoas não conseguem perceber a Ciência e a Tecnologia na cidade é porque Ihes falta a devida compreensão do quanto uma cidade é exemplo e um espaço que se altera em função da Ciência e da Tecnologia. É preciso compreender o quanto somos dependentes da CT e o quanto a cidade se modifica a partir delas. Além disso, a nossa pesquisa buscou entender a cidade como um espaço educacional, pois acreditamos que a cidade pode ser considerada um grande Museu Aberto de CT e que pode ser utilizada pela escola para esse fim.

Mas, como considerar a cidade um museu aberto de CT se nem mesmo os membros de uma comunidade universitária conseguem "enxergar" que temos vários 
elementos relacionados à CT na cidade? Talvez este seja o papel da escola, isto é, trazer para a sala de aula a discussão e exemplificação da CT em "coisas" simples, que fazem parte do nosso cotidiano, relacionando essas "coisas" com conceitos científicos escolares.

\section{REFERÊNCIAS}

BALDIN, Nelma; MUNHOZ, Elzira M. Bagatin. Snowbaal (Bola de Neve): uma técnica metodológica para pesquisa em educação ambiental comunitária. Anais do $\mathrm{X}$ Congresso Nacional de Educação - EDUCERE, I Seminário Internacional de Representações Sociais, Subjetividade e Educação. Pontifícia Universidade Católica do Paraná, Curitiba. 2011.

BAZZO, Walter Antonio; PEREIRA, Luiz Teixeira do Vale; VON LINSINGEN, Irlan. Educação Tecnológica: enfoques para o ensino de engenharia. Florianópolis: Ed. da UFSC, 2000.

CANDÉO, Manuella; SILVEIRA, Rosemari Monteiro Castilho Foggiatto; MATOS, Eloíza Aparecida Silva Ávila de. Relações sociais da Ciência e da Tecnologia: percepções dos professores de formação técnica participantes do PARFOR. Amazônia, Revista de Educação em Ciências e Matemáticas, V. 11, N. 21, p. 70 - 91, 2014.

CENTRO DE GESTÃO E ESTUDOS ESTRATÉGICOS - CGEE. Percepção pública da C\&T no Brasil: 2019. Resumo executivo. Brasília, DF, 2019. Disponível em: 
<https://www.cgee.org.br/documents/10195/734063/CGEE_resumoexecutivo_Perc epcao_pub_CT.pdf>. Acesso em: 19 de setembro de 2021.

CUNHA, Marcia Borin; CECATTO, Ana Julia; CONERADO, Douglas Henrique Santos. A Ciência e a Tecnologia na voz de entrevistados de uma amostra não probabilística. In: MACEDO, Beatriz; SILVEIRA, Sara; MEZIAT, Daniel; ASTETE, Margarita García; BENGOCHEA, Luís. Enseñanza y Aprendizaje de las Ciencias en Debate. Uruguai, p. 82 $-90,2019$.

GORDILLO, Martín, Mariano; RAMIREZ, Arribas, Ricardo, Arribas; ÁlVAREZ, Álgel, Camacho.; GARCÍA, Eloy, Fernandez. Ciencia, tecnología y sociedad. Madrid: Grupo Editorial Norte, 2001.

LEFEBVRE, Henri. O direito à cidade. Tradução Rubens Eduardo Frias, São Paulo: Centauro, p. $40-60,2001$.

PEREZ, Daniel Gil; MONTORO, Isabel Fernández; ALÍS Jaime Carrascosa; CACHAPUZ, António; PRAIA, João. Para uma imagem não deformada do trabalho científico. Ciência e Educação, V. 7, N. 2, p. $125-153,2001$.

WITHEY, Stephen B. Public opinion about science and scientists. Public Opinion Quarterly. N. 23, p. $382-388,1959$. 
